\title{
High Risk Behaviors for HIV and STIs Among Men Who Have Sex with Men Aged 15-19 Years - Guangzhou City and Tianjin Municipality, China, 2018
}

\author{
Hui Liu'; G. Johnston Lisa²; Lei Zhang'; Mengjie Han",; Hao Zhu'; Jie Yang5; \\ Jingyan $\mathrm{Li}^{6}$; Lu Liu'; Yujing Liu'; Mark Prabhu Shirley ${ }^{7}$
}

\section{Summary \\ What is already known on this topic? \\ There has been a steady increase of new reported HIV infections in individuals aged 15-24 years, primarily from self-reported men who have sex with men (MSM). \\ What is added by this report? \\ MSM aged 15-19 years practiced behaviors that put them at high risk for HIV and other sexually transmitted infections (STIs). Systems to address their unique risks and vulnerabilities in both school settings and in high impact HIV interventions may be inadequate. \\ What are the implications for public health practice? \\ Special needs of MSM aged 15-19 years must be met by starting sex education in junior high school and sensitizing health workers in and out of school settings on quality counselling, testing, and referral. Piloting approaches that address age of consent issues are also suggested.}

Adolescents and young people represent a growing share of people living with human immunodeficiency virus (HIV) globally (1). In China, new reported HIV cases among Chinese youth aged 15-24 years reached 16,307 in 2017 (2). The 2016 sentinel surveillance indicated that $82 \%$ of newly reported HIV cases among students were among males who reported having sex with males (MSM) (3). Of new HIV cases diagnosed in China, the male to male sexual transmission rate increased from $3.4 \%$ in 2007 to $28.2 \%$ in 2015 , and remained at around $28.2 \%$ from 2017 to 2018. (4). Also, China has 146 million adolescents, the second largest adolescent population in the world (5), but the population of adolescent MSM (AMSM) in China has not been well-studied. In 2018, an online survey was conducted in Guangzhou City and Tianjin Municipality to measure risk factors and behaviors for HIV and STIs to better plan prevention programs and service.

Eligible participants were male, aged 15-19 years, reported having oral or anal sex with a male in the past 12 months, and were living or working in Guangzhou or Tianjin. Online sampling used standard respondent driven sampling (RDS) method (G), which are a chain referral method used to sample members of hidden and hard-to-reach populations starting by choosing 'seed' participants who have large social networks and are well-known within their communities ( 7 ). Once the seed participants complete the survey, they are asked to recruit a set number of their eligible peers (usually up to three) using a uniquely coded coupon. Ongoing successive recruitment of peers results in multiple recruitment waves with the intended goal of eliminating common chain referral biases by the time the calculated sample size is reached. A payment system is used to remunerate participants for completing the survey (primary) and for successfully recruiting eligible participants (secondary).

Due to the hidden nature and vulnerability of AMSM and the popularity of online social networks among this age group in China, this study used a webbased peer-to-peer probability-based sampling technique using WeChat, a Chinese multi-purpose messaging, social media, and mobile payment app. The surveys were conducted in Tianjin (2015 population: $14,722,100)$ and Guangzhou (2015 population: $12,926,800)$, both of which have a strong presence of community-based organizations (CBOs) and adolescent networks and are also program sites for the China Comprehensive AIDS Response (China CARES) and UNICEF's adolescent HIV prevention collaboration with the Chinese government. Formative research and training were conducted with managers from $\mathrm{CBOs}$ and adolescent representatives from Guangzhou and Tianjin to identify potential sampling 
issues related to RDS, to resolve study logistics, to determine AMSM web-use behaviors for rolling out the surveys online, and to design the questionnaire.

A WeChat-based online program accessible via quick response $(\mathrm{QR})$ code was developed and rolled out by CBOs in the two cities. Respondents who received a valid recruitment e-coupon could scan their unique $\mathrm{QR}$ code and respond to a set of eligibility questions. Eligible persons were then requested to read the purpose of the survey and provide informed consent, and complete the online questionnaire. Those who completed the entire questionnaire received an 8digit password for an online payment of $30 \mathrm{CNY}$ $(-4.24$ USD) via Alipay, administered by the survey software manager. After completing the questionnaire, the respondent received up to 5 coupons with unique QR codes which were used to recruit eligible peers into the survey. Respondents received an additional incentive of $30 \mathrm{CNY}$ for each person they recruited who enrolled and completed the survey. These incentives were also provided online via Alipay and administered by the software manager.

No personal identifying information was collected, no response could be traced back to respondents, and, to avoid duplicates, each IP address could only enroll once. The questionnaire collected data on sociodemographic characteristics, social network sizes, use of MSM social networks, sexual and drug risk, knowledge on HIV and testing services, sexual experiences, perceptions, experience with buying and selling sex, condom use, social support, and access to

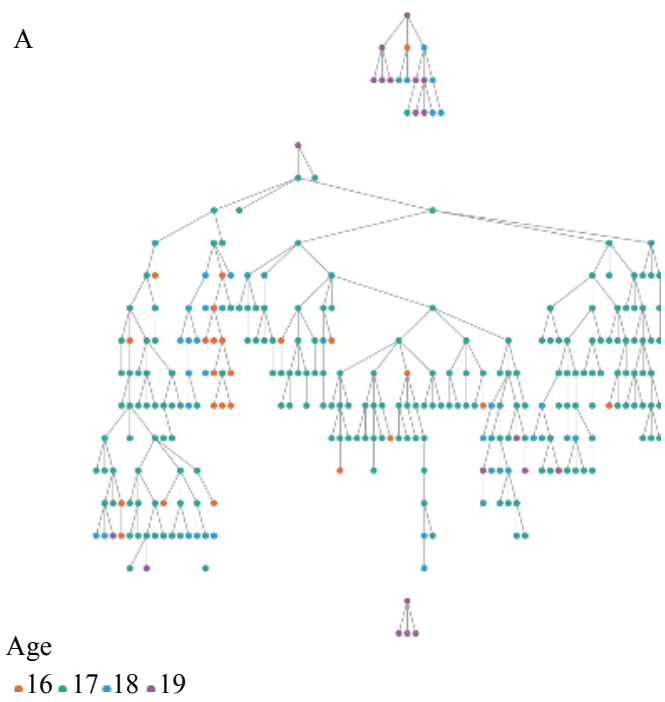

and utilization of HIV related services.

Data were directly entered into a database as participants responded to the online questionnaire. Data were monitored by an information technology manager as well as the survey coordinator and an international consultant. Data were formatted and coded in Microsoft Excel (version 14.0; Microsoft Corporation) and SPSS (version 23.0; IBM Corporation) before being downloaded into RDSAnalyst (www.hpmrg.org), a specialized software for analysing RDS data. Data were assessed for bottlenecks and convergence and population proportions, and 95\% confidence intervals (CI) were derived with RDSanalyst using the Gile successive sampling estimator (8-9) adjusted for differential recruitment and social network sizes. Given that the online survey format resulted in some unreliable social network size responses, social network sizes were imputed with the visibility imputation function in RDS Analyst (10). This survey received ethical approval from the ethics review committee of the National Centre for AIDS/STD Control and Prevention of China CDC.

The survey in Guangzhou recruited 288 MSM aged 15-19 years resulting in 3 recruitment chains with a maximum of 13 waves. In Tianjin, 258 were recruited resulting in 5 recruitment chains and a maximum of 9 waves (Figure 1A and Figure 1B, highlighted by age groups). The mean age of MSM aged 15-19 years was 17 years old in Guangzhou and 18 years old in Tianjin. Homosexual identity was reported by $32 \%$ of MSM aged 15-19 years in Guangzhou and 69\% in Tianjin. Most respondents reported that their parents

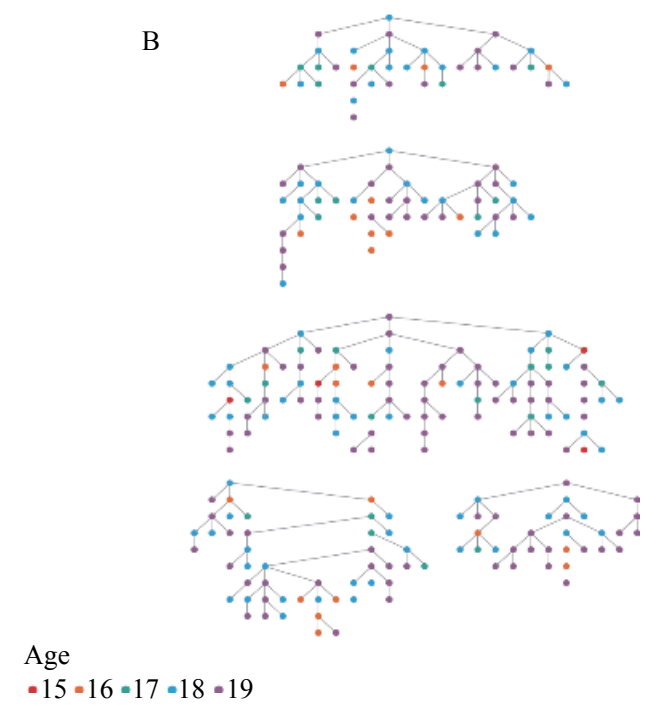

FIGURE 1. Recruitment chains of adolescent men who have sex with men (AMSM) sampling in Guangzhou, April-May, $2018(n=288)(A)$ and in Tianjin, April-September, $2018(n=258)(B)$. 
did not know about their sexual attraction to males, and $75 \%$ of MSM aged 15-19 years in Guangzhou and more than $94 \%$ in Tianjin reported using any MSM online social network app (Table 1).

The age group with the highest percentage for first anal sexual experience was 16 years old in Guangzhou and 18 years old in Tianjin. Most MSM aged 15-19 years in the 2 cities reported having had an anal sexual experience in the past 6 months, with over half having multiple sex partners. One third of respondents in both cities who reported having anal sex were primarily receptive partners. Forty-two percent of AMSM in Guangzhou and 9\% of AMSM in Tianjin reported experience of selling sex. Among them 56\% and 54\% reported having consistent condom use respectively. Among MSM aged 15-19 years who ever used a condom, the age at first condom use during an anal sexual experience most frequently reported was 16 years in Guangzhou and 18 years in Tianjin. An estimated $61 \%$ of AMSM in Guangzhou and $43 \%$ in Tianjin reported using any drug before anal sex with a male. Although as much as 65\% of MSM aged 15-19 years in Guangzhou and 93\% in Tianjin knew that the proper use of condoms during each sexual intercourse reduces the risk of HIV transmission, only $26 \%$ of MSM aged 15-19 years in Guangzhou and 12\% in

TABLE 1. Sociodemographic characteristics and communication factors of adolescent men who have sex with men (AMSM) in Guangzhou City and Tianjin Municipality, 2018.

\begin{tabular}{|c|c|c|c|c|}
\hline \multirow{2}{*}{ Item } & \multicolumn{2}{|c|}{ Guangzhou (n=288) } & \multicolumn{2}{|c|}{ Tianjin $(n=258)$} \\
\hline & $\mathbf{N}$ & Percentage (Cl) & $\mathbf{N}$ & Percentage (Cl) \\
\hline \multicolumn{5}{|l|}{ Currently in school } \\
\hline Yes & 270 & $94.7(91.9-97.5)$ & 228 & $83.1(79.9-94.3)$ \\
\hline No & 18 & $5.3(2.5-8.1)$ & 30 & $12.9(5.7-20.1)$ \\
\hline \multicolumn{5}{|l|}{ Education level } \\
\hline$\leq$ Junior high school & 58 & $19.1(13.8-24.4)$ & 18 & $8.0(2.2-13.9)$ \\
\hline Senior high/vocational/second & 202 & $71.2(65.2-77.2)$ & 105 & $46.0(35.8-56.2)$ \\
\hline$\geq$ Vocational college & 28 & $9.6(5.4-14)$ & 135 & $46.0(35.5-56.5)$ \\
\hline \multicolumn{5}{|l|}{ Sexual orientation } \\
\hline Gay/homosexual & 96 & $32.1(25.2-38.9)$ & 173 & $68.7(59.2-78.2)$ \\
\hline Bisexual & 59 & $24.1(16.8-31.3)$ & 45 & $18.0(10.1-25.8)$ \\
\hline Straight & 51 & $17.2(11.5-23)$ & 2 & $2.9(0-6.6)$ \\
\hline Unsure & 43 & $17.2(11.7-22.8)$ & 18 & $7.2(2.1-12.4)$ \\
\hline Other & 5 & $1.8(0-3.9)$ & 2 & $0.3(0-0.7)$ \\
\hline Do not know & 16 & $7.5(2.5-12.6)$ & 3 & $2.9(0-6.7)$ \\
\hline \multicolumn{5}{|c|}{ Talked about same sex behaviour among circle of friends } \\
\hline Yes & 143 & $55.2(48.2-62.4)$ & 129 & $57.7(46.4-68.9)$ \\
\hline No & 121 & $44.8(37.6-51.8)$ & 110 & $42.3(31.1-53.6)$ \\
\hline \multicolumn{5}{|c|}{ Parents know about sexual attraction to males } \\
\hline Yes & 101 & $39.8(31.4-48.2)$ & 30 & $11.2(3.8-18.4)$ \\
\hline No & 163 & $60.2(51.8-68.6)$ & 210 & $88.8(81.6-96.2)$ \\
\hline \multicolumn{5}{|l|}{ How MSM network was entered } \\
\hline Acquaintances outside school & 83 & $28.7(21.5-25.9)$ & 14 & $7.3(3.2-11.5)$ \\
\hline Classmates & 72 & $25.2(18.5-32)$ & 34 & $12.4(6.9-17.8)$ \\
\hline From internet & 75 & $28.6(20.3-36.9)$ & 174 & $64.2(55.9-72.5)$ \\
\hline Other & 3 & $1.9(0-4.2)$ & 5 & $2.6(0-5.7)$ \\
\hline Can't remember & 45 & $15.6(9.6-21.5)$ & 29 & $13.5(7.7-19.2)$ \\
\hline \multicolumn{5}{|l|}{ Uses any MSM online social network app } \\
\hline Yes & 215 & $74.7(67.5-81.9)$ & 252 & $94.3(88.8-99.9)$ \\
\hline No & 73 & $25.3(18.2-32.5)$ & 6 & $5.7(0.1-11.2)$ \\
\hline
\end{tabular}


Tianjin knew that a healthy-looking person can have HIV, and only $27 \%$ of AMSM in Guangzhou and $25 \%$ in Tianjin knew that having sex with one faithful, uninfected partner, reduces the risk of HIV transmission. Percentages of MSM aged 15-19 years in Tianjin who were aware of anti-retroviral therapy and self-testing for HIV were $91.6 \%$ and $85.6 \%$, respectively, whereas in Guangzhou the awareness rates of anti-retroviral therapy and HIV self testing were $59.5 \%$ and $45.8 \%$, respectively. The percentages of MSM aged 15-19 years reporting ever having a HIV test were $46.9 \%$ in Guangzhou and $79.4 \%$ in Tianjin. Self-reported positive results of HIV was $17.6 \%$ in Guangzhou and $2.1 \%$ in Tianjin (Table 2).

TABLE 2. HIV-related knowledge/awareness and behaviours among adolescent men who have sex with men (AMSM) in Guangzhou City and Tianjin Municipality, 2018.

\begin{tabular}{|c|c|c|c|c|}
\hline \multirow{2}{*}{ Item } & \multicolumn{2}{|c|}{ Guangzhou (n=288) } & \multicolumn{2}{|c|}{ Tianjin $(n=258)$} \\
\hline & $\mathbf{N}$ & Percentage (CI) & $\mathbf{N}$ & Percentage (Cl) \\
\hline \multicolumn{5}{|l|}{ Age at first anal sexual experience } \\
\hline$\leq 12$ years & 18 & $6.1(3.1-9.1)$ & 4 & $3.0(0-7.2)$ \\
\hline 13 years & 10 & $2.6(0.6-4.8)$ & 8 & $1.4(0-3.0)$ \\
\hline 14 years & 25 & $9.9(5.7-14.1)$ & 7 & $3.9(0.5-7.3)$ \\
\hline 15 years & 44 & $16.5(10.9-22.1)$ & 30 & $7.3(2.5-19.5)$ \\
\hline 16 years & 63 & $22.1(16-28.1)$ & 39 & $12.6(5.7-17.8)$ \\
\hline 17 years & 49 & $21.2(14.9-27.5)$ & 40 & $11.4(5.0-17.8)$ \\
\hline 18 years & 28 & $10.1(5.8-14.3)$ & 62 & $30.2(20.1-40.4)$ \\
\hline 19 years & 6 & $2(0.3-3.6)$ & 29 & $11.0(4.5-18.7)$ \\
\hline Do not remember & 25 & $9.6(5.5-13.6)$ & 25 & $18.5(9.9-27.2)$ \\
\hline \multicolumn{5}{|c|}{ Age at first use of condom during anal sexual experience } \\
\hline$\leq 12$ years & 10 & $3.5(0.4-6.6)$ & 2 & $2.3(0-7.8)$ \\
\hline 13 years & 8 & $3.0(0-6.3)$ & 4 & $1.2(0-3.5)$ \\
\hline 14 years & 16 & $9.1(3.0-15.2)$ & 7 & $3.1(0.2-6.1)$ \\
\hline 15 years & 39 & $20.4(10.2-30.5)$ & 17 & $4.6(1.4-7.8)$ \\
\hline 16 years & 68 & $28.5(20.0-37.0)$ & 32 & $16.0(8.8-23.1)$ \\
\hline 17 years & 53 & $19.4(11.6-27.1)$ & 38 & $12.8(7.8-17.8)$ \\
\hline 18 years & 33 & $12.6(5.5-19.7)$ & 57 & $31.6(23.7-39.6)$ \\
\hline 19 years & 12 & $3.5(0-7.0)$ & 53 & $28.3(20.4-36.2)$ \\
\hline \multicolumn{5}{|l|}{ Anal sexual experience in the past 6 months } \\
\hline Yes & 211 & $78.6(73.1-84)$ & 233 & $91.0(84.4-97.5)$ \\
\hline No & 59 & $21.4(16.0-26.8)$ & 11 & $9.0(2.5-15.6)$ \\
\hline \multicolumn{5}{|c|}{$\begin{array}{l}\text { Number of anal sex partners (among those who had anal sex in past } 6 \\
\text { months) }\end{array}$} \\
\hline 1 & 102 & $48.2(39.5-56.9)$ & 87 & $42.8(30.2-55.3)$ \\
\hline $2-5$ & 58 & $25.7(18.3-33.1)$ & 98 & $42.4(31.8-53.1)$ \\
\hline $6-10$ & 23 & $11(5.6-16.4)$ & 37 & $9.4(3.4-15.4)$ \\
\hline $11-20$ & 24 & $12.8(7.2-18.3)$ & 7 & $1.5(0-3.3)$ \\
\hline 21 and above & 4 & $2.3(1.4-3.3)$ & 4 & $4.0(0-8.8)$ \\
\hline \multicolumn{5}{|l|}{ Age range of sex partners ${ }^{*}$ in past 6 months } \\
\hline Under 20 years & 185 & $68.6(61.5-75.8)$ & 110 & $45.5(35.4-55.6)$ \\
\hline $20-30$ years & 53 & $18.3(12.3-24.2)$ & 113 & $47.6(37.0-58.0)$ \\
\hline $31-40$ years & 26 & $10.1(6.2-14.1)$ & 9 & $6.9(0.9-12.9)$ \\
\hline 41 years or above & 6 & $2.9(0.6-5.3)$ & 1 & $0.1(0-0.2)$ \\
\hline
\end{tabular}


TABLE 2. (Continued)

\begin{tabular}{|c|c|c|c|c|}
\hline \multirow{2}{*}{ Item } & \multicolumn{2}{|c|}{ Guangzhou (n=288) } & \multicolumn{2}{|c|}{ Tianjin $(n=258)$} \\
\hline & $\mathbf{N}$ & Percentage (Cl) & $\mathbf{N}$ & Percentage (Cl) \\
\hline \multicolumn{5}{|c|}{ Usual role in anal sex experience in past 6 months } \\
\hline Insertive & 93 & $40.6(30.2-50.9)$ & 77 & $37.4(26.6-48.4)$ \\
\hline Receptive & 70 & $33.8(23.1-44.5)$ & 97 & $38.0(27.348 .7)$ \\
\hline Insertive and receptive & 46 & $25.6(17.0-34.2)$ & 54 & $24.6(15.2-33.9)$ \\
\hline \multicolumn{5}{|l|}{ Ever paid someone money for sex } \\
\hline Yes & 117 & $44.6(37.0-52.4)$ & 13 & $5.3(0.2-10.5)$ \\
\hline No & 148 & $55.4(47.7-63)$ & 228 & $94.7(89.5-99.8)$ \\
\hline \multicolumn{5}{|c|}{ Frequency of using a condom when paying for sex } \\
\hline Every time & 74 & $57.9(47.0-69.0)$ & 2 & $29.2(0-76.2)$ \\
\hline Sometimes & 37 & $36.5(25.5-47.4)$ & 7 & $38.8(0-76.0)$ \\
\hline Never & 6 & $5.6(5.6-5.6)$ & 4 & $32.0(0-73.4)$ \\
\hline \multicolumn{5}{|c|}{ Ever received money or other benefit in return for sex } \\
\hline Yes & 112 & $41.7(33.2-50.1)$ & 21 & $9.4(2.4-16.4)$ \\
\hline No & 153 & $58.4(49.9-66.8)$ & 220 & $90.6(83.6-97.6)$ \\
\hline \multicolumn{5}{|c|}{ Frequency of using a condom when selling sex } \\
\hline Every time & 65 & $55.5(39.3-71.7)$ & 10 & $53.6(25.8-81.6)$ \\
\hline Sometimes & 40 & $39(27.6-50.5)$ & 10 & $45.1(17.2-72.8)$ \\
\hline Never & 7 & $5.5(0-14.2)$ & 1 & $1.3(0.4-2.2)$ \\
\hline \multicolumn{5}{|c|}{ Ever been forced or coerced to have anal sexual experience with a male } \\
\hline Yes & 116 & $43.7(35.0-52.2)$ & 19 & $8.8(3.8-13.8)$ \\
\hline No & 148 & $56.4(47.7-65.0)$ & 222 & $91.2(86.2-96.2)$ \\
\hline \multicolumn{5}{|c|}{ Frequency of condom use when forced to have anal sexual experience } \\
\hline Every time & 66 & $58.3(44.5-72.1)$ & 9 & $53.5(26.6-80.5)$ \\
\hline Sometimes & 42 & $36.5(23.7-49.4)$ & 3 & $18.3(3.8-40.4)$ \\
\hline Never & 8 & $5.2(1.2-9.0)$ & 7 & $28.2(14.2-42.2)$ \\
\hline \multicolumn{5}{|c|}{ Can always negotiate with a partner to use condoms when wanting to } \\
\hline Yes & 185 & $74.9(67.8-82.1)$ & 212 & $88.7(83.3-94.1)$ \\
\hline No & 46 & $21.4(15.3-27.5)$ & 17 & $9.0(3.8-14.2)$ \\
\hline Never want to use & 9 & $3.7(0.2-7.2)$ & 6 & $2.3(0-4.7)$ \\
\hline \multicolumn{5}{|c|}{ Used a condom during last anal sexual experience } \\
\hline Yes & 206 & $85.3(78.4-92.2)$ & 143 & $62.7(51.1-74.3)$ \\
\hline No & 34 & $14.7(7.8-21.6)$ & 93 & $37.3(25.7-48.9)$ \\
\hline \multicolumn{5}{|c|}{ Used any drug before anal sex with a man to enhance sexual experience } \\
\hline Yes & 160 & $61.4(53.6-69.3)$ & 107 & $42.5(32.9-52.3)$ \\
\hline No & 105 & $38.6(30.7-46.4)$ & 135 & $57.5(47.4-67.2)$ \\
\hline \multicolumn{5}{|c|}{ Awareness that a healthy-looking person can have HIV } \\
\hline Yes & 75 & $25.7(19.0-32.4)$ & 33 & $12.2(5.3-19.2)$ \\
\hline No & 130 & $50.4(42.7-58.2)$ & 184 & $73.7(64.6-82.7)$ \\
\hline Do not know & 65 & $23.9(19.0-30.8)$ & 27 & $14.1(6.9-21.4)$ \\
\hline
\end{tabular}




\begin{tabular}{|c|c|c|c|c|}
\hline \multirow{2}{*}{ Item } & \multicolumn{2}{|c|}{ Guangzhou ( $n=288$ ) } & \multicolumn{2}{|c|}{ Tianjin $(n=258)$} \\
\hline & $\mathbf{N}$ & Percentage (Cl) & $\mathbf{N}$ & Percentage (Cl) \\
\hline \multicolumn{5}{|c|}{$\begin{array}{l}\text { Awareness that having sex with one faithful-uninfected partner reduces the } \\
\text { risk of HIV transmission }\end{array}$} \\
\hline Yes & 94 & $26.6(26.7-39.2)$ & 45 & $25.3(15.8-34.7)$ \\
\hline No & 101 & $37.8(30.3-45.3)$ & 178 & $65.3(55.0-75.7)$ \\
\hline Do not know & 75 & $29.3(21.7-36.9)$ & 21 & $9.4(3.3-15.4)$ \\
\hline \multicolumn{5}{|c|}{$\begin{array}{l}\text { Awareness that proper use of condoms during each sexual experience } \\
\text { reduces the risk of HIV transmission }\end{array}$} \\
\hline Yes & 180 & $65.3(57.8-72.7)$ & 231 & $93.4(88.1-98.6)$ \\
\hline No & 51 & $20.9(15.5-26.2)$ & 8 & $3.4(0-7.0)$ \\
\hline Do not know & 39 & $13.9(7.4-20.3)$ & 5 & $3.2(0-6.9)$ \\
\hline \multicolumn{5}{|l|}{ Aware of anti-retroviral therapy } \\
\hline Yes & 167 & $59.5(51.3-67.6)$ & 216 & $91.6(86.3-96.8)$ \\
\hline No & 103 & $40.5(32.4-48.7)$ & 28 & $8.5(3.2-13.7)$ \\
\hline \multicolumn{5}{|c|}{ Aware of a test to take by oneself to test for HIV } \\
\hline Yes & 128 & $45.8(37.1-54.5)$ & 201 & $85.6(78.5-92.6)$ \\
\hline No & 142 & $54.2(45.5-62.9)$ & 43 & $14.4(7.4-21.5)$ \\
\hline \multicolumn{5}{|l|}{ Ever tested for HIV } \\
\hline Yes & 123 & $46.9(37.4-56.2)$ & 198 & $79.4(70.5-88.3)$ \\
\hline No & 141 & $53.2(43.8-62.6)$ & 47 & $20.7(11.7-29.5)$ \\
\hline \multicolumn{5}{|c|}{ Result of last test (among those who ever had an HIV test) } \\
\hline Negative & 78 & $59.7(45.7-73.6)$ & 183 & $84.1(76.8-91.3)$ \\
\hline Positive & 22 & $17.6(9.8-25.3)$ & 4 & $2.1(0-5.5)$ \\
\hline Do not know results & 23 & $22.8(11.6-33.9)$ & 11 & $8.3(0.3-16.4)$ \\
\hline \multicolumn{5}{|l|}{ Self-perceived level of HIV infection risk } \\
\hline No risk & 51 & $18.8(13.4-24.1)$ & 43 & $18.6(9.4-27.9)$ \\
\hline Some risk & 116 & $47.9(41.3-54.6)$ & 91 & $36.3(26.3-46.2)$ \\
\hline High risk & 63 & $25.2(18.5-31.9)$ & 75 & $30.9(19.9-41.9)$ \\
\hline Do not know & 0 & - & 17 & $8.3(1.9-14.7)$ \\
\hline
\end{tabular}

* Type of sex is not defined; sex of partner not defined; question asks about multiple partners whose ages may not be in the same range.

\section{DISCUSSION}

This survey found that AMSM have many intersecting risks including high percentage of inconsistent condom use during anal sex, of early sexual initiation, of recreational drug use, and use of sexual enhancement drugs that are likely leading to unprotected sex or sex with multiple partners. They also have high rates of self-reported HIV infection.

These findings strongly indicated that education on STI/HIV prevention and on risks of drug use must begin at younger ages. Educators in school settings must be trained on and sensitized to the specific needs for knowledge of and services for AMSM and other key adolescent populations to provide early and targeted interventions in response to the high prevalence of risky sex and substance abuse. Both AMSM and service providers should be informed about the actual age of consent of 16 years for independent testing, to encourage more adolecents at high risk of HIV to get tested and receive counselling. In addition, utilization of self-testing should be explored for AMSM.

Because AMSM have large social networks and rely on peers for information, more activities should be explored on how to use the highly active social networks and peer communications to improve AMSM's knowledge and access to services. Creative technology-based interventions should be enhanced to 
leverage social media to expand and improve connections with AMSM, to better understand their behaviors, to more effectively disseminate knowledge on HIV prevention, counselling, and testing, and to improve access to services.

This survey had some limitations. Although recruitment through peers using WeChat was effective, the reporting of accurate network sizes could not be verified. Some variables had small values, which resulted in wide confidence intervals that limited the ability to derive accurate estimates. However, this is the first use of online RDS among AMSM in China and provides essential information about their behaviors and needs. Additional surveys using online techniques should be conducted in other cities to gain a more expanded epidemiological picture of AMSM in China.

Acknowledgments: We would like to show our gratitude to Haichao Zhang and Lingping Cai of Beijing Kangzhong Health Education and Service Centre for the design and management of the online system for this web-based survey, and we thank Liqiu Wang, an independent researcher and programme specialist, and Peng Liu of the Chinese Association for STD/AIDS Prevention and Control for their insight and technical advice. We are immensely grateful to UNICEF China and UNICEF East Asia and Pacific Regional Office for their generous funding support and technical advice, and to the Global AIDS Programme (GAP), United States CDC, China Office for their technical expertise around this subject matter. doi: $10.46234 /$ ccdcw2020.124

\# Corresponding author: Mengjie Han, mjhan@chinaaids.cn.

\footnotetext{
${ }^{1}$ National Centre for AIDS/STD Control and Prevention, Chinese Center for Disease Control and Prevention, Beijing, China;

${ }^{2}$ University of California, San Francisco, Global Health Sciences, San
}

Francisco, USA; ${ }^{3}$ UNICEF China, Beijing, China; ${ }^{4}$ United States CDC, China Office, Beijing, China; ${ }^{5}$ Tianjin Shenlan Public Health Counseling Service Centre, Tianjing, China; ${ }^{6}$ Lingnan Partners, Guangzhou, China; ${ }^{7}$ UNICEF East Asia and Pacific Regional Office, Bangkok, Thailand.

Submitted: December 20, 2019; Accepted: June 15, 2020

\section{REFERENCES}

1. UNICEF. Turning the tide against AIDS will require more concentrated focus on adolescents and young people. https://data.unice f.org/topic/hivaids/adolescents-young-people/. [2020-06-02].

2. Health Correspondence from Xinhua News Agency. HIV is hitting the young - how should we respond? https://news.china.com/zw/news/ 13000776/20181202/34569944.html. [2018-12-2]. (In Chinese).

3. National Centre for AIDS/STD Control and Prevention, China CDC. http://ncaids.chinacdc.cn/jb/fzdt/mtbd/201711/t20171120_155051.ht m. [2020-06-02]. (In Chinese).

4. Wu ZY. Characteristics of HIV sexually transmission and challenges for controlling the epidemic in China. Chin J Epidemiol 2018;39(6):709 9. http://dx.doi.org/10.3760/cma.j.issn.0254-6450.2018.06.002. (In Chinese).

5. UNICEF China, UNFPA China. Population Status of Adolescents in China in 2015: Facts and Figures. https://www.unicef.cn/media/8856/ file $/ 2015 \% 20$ Adolescent $\% 20$ Population $\% 20$ Status $\% 20$ Facts\&Figures. pdf. [2020-06-02].

6. Johnston LG. Introduction to Respondent Driven Sampling. Introduction to HIV/AIDS and sexually transmitted infection surveillance. World Health Organization Regional Office for the Eastern Mediterranean. Geneva Switzerland; 2013. http://applications. emro.who.int/dsaf/EMRPUB_2014_EN_1686.pdf. [2020-06-02].

7. Heckathorn DD. Respondent-driven sampling: a new approach to the study of hidden populations. Soc Probl 1997;44(2):174-99. http://dx.doi.org/10.2307/3096941.

8. Gile KJ, Handcock MS. Respondent-driven sampling: an assessment of current methodology. Sociol Methods 2010;40(1):285 - 327. http://dx.doi.org/10.1111/j.1467-9531.2010.01223.x.

9. Gile KJ, Johnston LG, Salganik MJ. Diagnostics for respondent-driven sampling. J Roy Stat Soc Ser A Stat Soc 2015;178(1):241-69. http://dx.doi.org/10.1111/rssa.12059.

10. McLaughlin KR, Handcock MS, Johnston LG. Inference for the visibility distribution for respondent-driven sampling. 2015. conference proceedings: joint statistical meetings proceedings. Social Statistics Section. https://pdfs.semanticscholar.org/f99f/9816e463cb8081562aff 3d0b5d527c5ddffd.pdf. [2020-06-02]. 